\title{
Análisis del funcionamiento de la Publicidad Below The Line en la Sociedad
}

\author{
Analysis the behavior of Below The Line advertising in Society
}

\author{
Dra. Mónica MATELLANES LAZO \\ Universidad Europea Miguel de Cervantes (España) \\ mmatellanes@uemc.es
}

Recibido: 8 de febrero de 2014

Aceptado y Publicado: 30 de marzo de 2014

\section{Resumen}

Este artículo hace un análisis del funcionamiento de la publicidad y los límites que la sociedad trata de imponerle. Esta reflexión se hace desde la sociología de la publicidad, considerando que ésta se ocupa de los efectos que produce la publicidad sobre la cultura personal y sobre el contexto cultural y social del consumidor. Se centra en el nuevo rol activo del consumidor publicitario en las nuevas acciones de comunicación below the line y cómo es la relación entre ambas partes. El artículo presenta los resultados de un análisis cualitativo de jóvenes estudiantes de Publicidad que buscan creativas acciones below the line de Marcas en Internet.

\section{Abstract}

This paper analysis the behavior of advertising and the limits society tries to impose over it. This cogitation is made from a sociological perspective, due to the fact that it deals with the effects that advertising generates over social contexts. It shows the new role of advertising consumer in below the line actions and how is the relationship each other. The article presents the results of a quantitative analysis of young people students of Publicity who search creative below the line actions by Internet.

Palabras Clave: Publicidad; Consumidor; Below the line; Marca; Cultura; Interacción. Key Words: Advertising; Consumer; Below the line; Brand; Culture; Interaction.

\section{Introducción}

La publicidad desempeña una gran importancia en el plano social. Incluso, podría decirse que es uno de los actores más potentes que actúan en el proceso de la producción de la 
cultura de la sociedad contemporánea. Esto conlleva que la publicidad tenga una gran visibilidad social y, a un mismo tiempo, que sea objeto de numerosas críticas. A lo largo de la historia, la publicidad ha tenido detractores por sus excesos en cuanto a la utilización de un lenguaje exagerado y agresivo o por el abuso de imágenes de las mujeres y de su cuerpo. Durante los años sesenta y setenta en Occidente la publicidad fue duramente criticada (Codeluppi, 1995: 58), además de que se extendió la idea de que los publicitarios, como hábiles profesionales de la publicidad, manipulaban con facilidad las mentes de los consumidores creándoles falsas necesidades de consumo (Galbraith, 1958 y Marcuse, 1964).

El periodista Vance Packard (1957) que escribió el libro The Hidden Persuador mantuvo esta teoría que aún hoy día sigue vigente en autores que critican el proceso actual de globalización económica y cultural (Lasn et al., 1999: 124).

Packard afirmó que los publicitarios podían actuar sobre el inconsciente de los individuos para condicionar su comportamiento a través de técnicas como la de la investigación motivacional. Esta visión exagerada de la publicidad se basa en el miedo que ésta inspira como un potente instrumento de comunicación. Es cierto, que la publicidad ejerce una influencia sobre el comportamiento de las personas, pero, también lo ejercen otros actores sociales. Siempre en última instancia es el consumidor el que decide lo consume a partir de los factores que le rodean.

La sociología de la publicidad se ocupa de los efectos que produce la publicidad sobre la cultura personal y sobre el contexto cultural y social del consumidor y no de la influencia de la publicidad sobre la decisión de compra del consumidor. $Y$, aunque en un principio podría parecer que la cultura y el contexto que no influyen sobre el consumo, en realidad son determinantes para la toma de decisión del consumidor.

La publicidad como efecto social es un tema que merece la pena ser tratado, más aún si consideramos el rol que juega hoy día el consumidor y receptor a la hora de consumir y producir mensajes publicitarios con gran contenido persuasivo. Es por ello que es de vital importancia tratar los nuevos formatos y canales de publicidad que abren la posibilidad a la interacción y a la participación mediática de los diferentes tipos de usuarios. Lo que se llama la comunicación por debajo de la línea o below the line (comunicación no convencional) y que se ve reflejado en acciones de street marketing y marketing de guerrilla.

\subsection{Funcionamiento de la Publicidad}

Facultad de Ciencias de la Información - Universidad de La Laguna

Avenida César Manrique, s/n; Campus de Guajara

38071 La Laguna, Tenerife (Islas Canarias - España) 
Actualmente la publicidad es consideradas como un instrumento de comunicación cuyo propósito es crear un ambiente y una disposición positiva por parte del consumidor, respecto a determinados productos o servicios y, además, que ello culmine con la adquisición de los mismos. La publicidad nunca actúa directamente sobre el comportamiento de los consumidores. Los publicitarios asocian significados e imágenes inmateriales a sus productos para dotarlos de imaginarios simbólicos. Y el consumidor hoy en día busca en los productos un conjunto de significados simbólicos como el éxito, el poder, la aceptación social y la belleza entre otros, más que la satisfacción de tipo funcional. De hecho, el consumidor no adquiere ningún producto o servicio que no haya tenido previamente una dosis de carga simbólica.

En este sentido la publicidad se limita a capturar los significados ya existentes en el colectivo imaginario y adaptarlos a los productos ofertados en el mercado de consumo. La publicidad presenta al producto como una entidad propia para lograr sus objetivos si éste tiene una fuerte identidad. En caso contrario, lo muestra junto a objetos, personas o situaciones sociales o afectivas cuyos significados sociales sean reconocidos por el consumidor. Tal como apuntó Roland Barthes (1957), esta construcción artificial de productos y servicios cargados de valores que no le son propios acaba siendo para nosotros del todo natural. Siguiendo este razonamiento, un producto carente de significado sólo necesita que se le asocie otro elemento con significación social. Por ejemplo, en el caso de un anuncio de perfume francés éste puede mostrarse junto a la Torre Eiffel, de manera que el simbolismo de este monumento se asocie directamente al perfume anunciado y el consumidor lo perciba como propio del perfume. Tal como afirma Corrigan (1997: 45) el producto representa una realidad y el consumidor necesita adquirirlo para sentirse vivo.

Actualmente en nuestra cultura, la publicidad puede entenderse como un actor que transmite al unísono significados y valores: primero al producto y, segundo, desde éste al consumidor a través de la compra. De manera que la publicidad esteriliza el producto porque lo transforma en atributos deseables para el consumidor y, posteriormente, estos atributos se transfieren al consumidor a través de la compra que, a su vez, le hacen deseable frente a los demás por poseer el producto.

Este proceso es factible gracias a la participación del consumidor, que actúa de forma activa como intérprete de los valores y significados asociados a los productos y servicios y no de forma pasiva. Por consiguiente, la publicidad necesita de distintas acciones del marketing y de nuevas vía de comunicación para que sus mensajes tengan mayor eficacia. Esto indica que no es tan potente como algunos creen. Aunque, esto no debe inducir a pensar que la publicidad no produzca efectos concretos, porque el mundo ideal que crea la publicidad no

Facultad de Ciencias de la Información - Universidad de La Laguna

Avenida César Manrique, s/n; Campus de Guajara

38071 La Laguna, Tenerife (Islas Canarias - España) 
es una mera herramienta para que los productos o servicios se adquieran, sino que, además, es un modelo que influye de forma directa sobre los individuos en su vida cotidiana y un poderoso instrumento de promoción y legitimación de la cultura del consumo (Baudrillard, 1987: 14-15).

\subsection{Las teorías de Pollay y Goffman}

Richard Pollay (1986) intentó categorizar las características de la publicidad que influyen en la sociedad. Éste identificó entre otras: la repetitividad y prominencia de sus mensajes, la profesionalidad de los mismos y la dispersión y heterogeneidad de sus públicos que cada vez están más distantes de los valores y de las instituciones sociales tradicionales. De acuerdo con estas características, la publicidad selecciona los elementos culturales que le resultan más interesantes para crear y promover valores sociales que le conviene y ridiculizar u olvidar aquellos poco acertados. En algunos casos, no crea valores sino que cambia o invierte la jerarquía de los valores reforzando aquellos que promueve y dejando sin significado los que no utiliza.

Para Pollay, la publicidad es un espejo deformante porque, a un mismo tiempo, reflexiona y modifica la cultura social. La publicidad es capaz de cambiar la atención individual y social sobre los temas de actualidad y, además, conseguir alterar los referentes personales con los que se da sentido a la realidad percibida. Según Pollay, la consecuencia final de la publicidad es la consolidación de valores negativos como el materialismo, el cinismo, la ansiedad o la competitividad social y la ausencia de respeto.

La visión de Pollay es excesivamente negativa hacia la publicidad. De hecho, actualmente se entiende que la influencia de la publicidad es similar a la de otras instituciones sociales que lanzan mensajes persuasivos como la televisión, la radio, el cine, la prensa etc. Además, se podría pensar que la publicidad tiene efectos sociales positivos como las campañas sociales que promueven valores de interés social. E incluso, como apunta Morris Holbrook (1987: 89), la publicidad refleja valores positivos, como la sociabilidad, el afecto, la generosidad, la salud, el patriotismo, el enriquecimiento personal, la seguridad o la templanza.

Todo esto no impide que Pollay haya captado la verdadera naturaleza del papel social que ejerce la publicidad, en cuanto espejo deformante con respecto a los valores sociales. Esto es propio de su naturaleza porque la publicidad representa la realidad de forma simple y reducida. Las personas que aparecen en los anuncios son irreales y encarnan clases sociales y estilos de vida abstractos, todo lo contrario que los personajes definidos en la literatura o en el cine. La publicidad tiene la necesidad de que se comprenda de inmediato su mensaje sin ambigüedad, por ello las expresiones faciales, las poses, los comportamientos o

Facultad de Ciencias de la Información - Universidad de La Laguna

Avenida César Manrique, s/n; Campus de Guajara

38071 La Laguna, Tenerife (Islas Canarias - España)

www.revistapangea.org | Pág. 25 
las situaciones que presentan los actores son lo más estándar posible. Según Goffman (1979: 59), la publicidad crea la denominada «hi-per-ritualización» porque refuerza la imagen social de las personas, sobre todo en el plano sexual, y las situaciones estereotipadas. Por ello, la publicidad es un poderoso instrumento que construye la realidad social (Giaccardi, 1995: 45-46).

Codeluppi, (1996: 29) y, como afirmaba Pollay, contribuye a debilitarla, a reforzar o modificar los valores culturales que utiliza. $\mathrm{Y}$ al mismo tiempo, es una de las instituciones culturales más importantes del mundo actual por la presencia prominente en los espacios sociales y por la repetición de sus mensajes.

\subsection{El efecto de la modernización de la publicidad}

Francesco Alberoni (1964) consideró que la publicidad puede ejercer una positiva influencia social como un instrumento de modernización de la sociedad. Permite que los ciudadanos acepten productos nuevos, e incluso que superen la inicial desconfianza psicológica hacia éstos.

La publicidad desarrolla una doble función: de un lado, induce ansiedad en los individuos por la aparición de nuevos productos (en los años sesenta Alberoni estudiaba la ansiedad provocada por nuevos productos como la lavadora que suponía para las amas de casa un desequilibrio respecto a sus deberes familiares) y, de otro lado, elimina esta ansiedad a través del lenguaje que hace más comprensible la cultura moderna y evita decir lo negativo porque siempre habla en positivo. Comunica desde la alegría y la serenidad asociando el producto a una feliz vida familiar.

De esta manera, la publicidad ayuda a que los individuos acepten las innovaciones y enfatiza sobre la gratificación en un plano psicológico y, a un mismo tiempo, estimula al cambio y a la adquisición de los nuevos bienes prometiendo a los consumidores que ellos no cambiarán.

La postura de Alberoni está presente en la publicidad. La publicidad contribuye a la aceptación del cambio social y a la modernización en cuanto a los usos y hábitos de los individuos. Ronald Berman (1981: 102-103) en esta línea afirma que la publicidad pone voz a la tecnología porque además de ser inventada tiene que ser comunicada. El papel de la publicidad es servir de puente entre la tecnología y el mercado. Y, además, ésta desarrolla una función ideológica que es la de mostrar los beneficios que trae consigo la tecnología.

Este mecanismo publicitario revelado por Alberoni sigue vigente en la actualidad. Por ello, debe representar todo lo que está presente en la cultura social, que a su vez es el reflejo de lo que piensan los individuos. Éstos no son sujetos pasivos que se dejan influenciar sin oponer resistencia; todo lo contrario, son sujetos activos que reelaboran y sintetizan los

Facultad de Ciencias de la Información - Universidad de La Laguna

Avenida César Manrique, s/n; Campus de Guajara

38071 La Laguna, Tenerife (Islas Canarias - España)

www.revistapangea.org | Pág. 26 
mensajes publicitarios recibidos con su propia cultura personal de forma totalmente individual.

Esto quizá ocurra por la propia naturaleza de la publicidad ya que se presenta de una forma explícita, sin esconderse, muy al contrario de la información periodística que, bajo el ropaje de la neutralidad informativa, ofrece datos de interés económicos y políticos sin dejar ver de quién o de qué parte se está. La publicidad establece un pacto con el interlocutor de manera que deja claras sus intenciones.

\subsection{Los nuevos canales de comunicación below the line para la Publicidad}

Los anunciantes observan como los medios de comunicación están cada vez más saturados de información publicitaria, los altos costes de los medios convencionales y la búsqueda de atraer al receptor para causar mayor impacto, hace que estén apostando cada vez hacia medios no tradicionales, los llamados formatos publicitarios por debajo de la línea, below the line. Ante esta situación el Ambient Marketing o Street Marketing se configuran como una solución de comunicación alternativa.

El ambient marketing es la respuesta de la publicidad a la creciente falta de interés que generan los espacios de publicidad convencionales, integrándose en el espacio urbano. No es publicidad exterior tradicional, ya que ésta sí tiene sus espacios muy delimitados, legislados y controlados por las empresas exclusivistas de explotación de los emplazamientos. Sin embargo, esta nueva tendencia de comunicación busca llamar la atención del receptor en plena calle, utilizando la ciudad como soporte de comunicación.

El ambient es un tipo de publicidad que está creciendo considerablemente en los últimos años. Se trata de utilizar como soporte de la comunicación cualquier elemento de nuestro entorno que no está específicamente pensado para ello. Así se logra destacar entre la multitud de anuncios que tratan de captar nuestra atención. Y porque además es un tipo de publicidad que da mucho juego a la creatividad, pues trata de utilizar medios convencionales del día a día, cualquier elemento del entorno y transformarlo en un reclamo para el consumidor (Cervera Fantoni, 2008 -115).

Por otro lado, el Street Marketing son acciones que tienen lugar en espacios públicos al igual que el ambient, con formatos cargados de emoción, creatividad, originalidad, sorpresa, pero que tratan de implicar al consumidor activamente en el contenido del mensaje mediante actividades inesperadas o poco usuales. 
En la actualidad, estos dos términos se confunden incluso entre los profesionales de las técnicas más agresivas de este tipo de Marketing o llamado también Marketing de guerrilla. La delgada línea en cuanto a la diferenciación existe y es en este sentido bastante notoria (Sánchez Herrera y Pintado, 2010: 45).

Se ha dicho que el Ambient Marketing escoge entornos y elementos del entorno público, pero hay que matizar un poco más; se parte de un elemento urbano de la ciudad que cumple una función social y urbanística para el ciudadano diario. Hasta aquí sencillo ya que se estaría hablando de publicidad exterior convencional, pero lo que añade de creativo el ambient marketing es la transformación de elementos urbanos para crear situaciones nuevas dentro de un nuevo contenido para la marca y que resulte simpático y diferente al transeúnte (Pacheco, 1998).

Por el contrario, en el street marketing se llevan a cabo insólitas acciones de comunicación con la técnica de la intrusión en su mayoría, ¿Qué quiere decir esto?, pues bien, el street se vale de actores y personajes humanos que recrean ambientes originales y llamativos para una marca, de modo que en muchas ocasiones hacen participar de forma activa al viandante en zonas públicas. Tal es el ejemplo de las técnicas llamadas flashmob y dance marketing. Son acciones multitudinarias de personas que se concentran en lugares públicos para bailar o hacer algo insólito, generalmente actores y bailarines que actúan con música para llamar la atención sobre un reclamo publicitario hacia una marca. En este caso, muchas veces la gente que lo ve en la calle o centros comerciales participa en este tipo de acontecimientos. Estas acciones suelen ser convocadas por medios telemáticos y digitales (smartphones e Internet), su finalidad es entretener y generar publicidad gratuita en medios mass media y fomentar la publicity (Pacheco, 1998).

\section{Metodología}

Se ha empleado una muestra de 105 estudiantes de la Facultad de Ciencias Humanas y de la Información de la Universidad Europea Miguel de Cervantes de Valladolid, que cursaban la asignatura de Marketing en Internet para valorar en 90 minutos las principales acciones below the line de Marcas reconocidas y encontradas en la red a través de varios directorios, enlaces, blogs, páginas web y revistas digitales.

Es un tipo de muestro no probabilístico o bola de nieve en el que los estudiantes entre 21 y 25 años debían escoger las acciones más creativas, impactantes y directas que fomentaban la interacción con el viandante o receptor. 
El estudio comenzó en marzo de 2013, durante las sesiones de cuatro clases de 90 minutos cada una en las que debían buscar, seleccionar y valorara las marcas que habían conseguido mayor impacto mediático a través de las acciones en las que se implicaba directamente al individuo. En el comienzo del verano del mismo año, se escogieron las cinco acciones más repetidas y mejor valoradas por los estudiantes.

Los objetivos eran ver la repercusión de estas acciones en medios digitales, la viralidad conseguida y el impacto provocado entre los más jóvenes. De esta forma, se podría conocer cuáles son las marcas que están llevando más acciones de este tipo en los últimos años.

Marcas como Heineken, Coca-Cola, Ikea, la Cadena de Televisión TNT, Solán de Cabras, son las empresas y marcas que mayor repercusión e inversión están realizando en este tipo de acciones de comunicación no convencionales y que además están consiguiendo mayor viralidad e impacto a la hora de ver las parodias realizadas por los propios internautas; lo que se llama el potenciador de la viralidad Apertura Remixi.

\section{Resultados}

A continuación se ofrecen los resultados más valorados por los estudiantes de Ciencias de la Información en cuanto a interacción y participación con el mensaje publicitario, efecto sorpresa y fomento de la comunicación viral en varios canales mediáticos.

Una de las más reconocidas fue la acción de ambient de lkea en el año 2011 en Estocolmo. El concepto creativo y el claim de la marca, La República Independiente de tu casa, aciertan con la transformación de la marquesina como si fuera la propia sala de estar de un hogar cualquiera. 


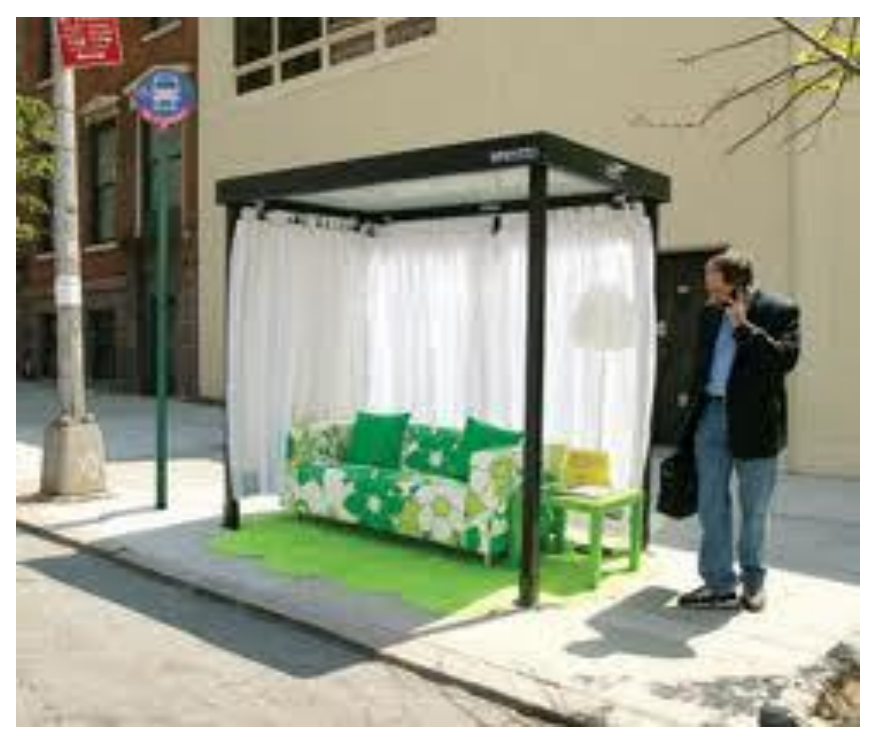

Figura 1. Marquesina transformada por la Marca Ikea en Estocolmo.

Fuente: www.google.es/imágenes

Otra de las campañas de Ambient Marketing no exentas de polémica fue la creada por la cadena de TV americana HBO para anunciar la serie The Sopranos.

Consistió en meter "cadáveres" en los taxis en circulación por las calles de New York. Esto generó admiración y causó expectante viralidad, pero la gente también hablaba del mal gusto de la acción.

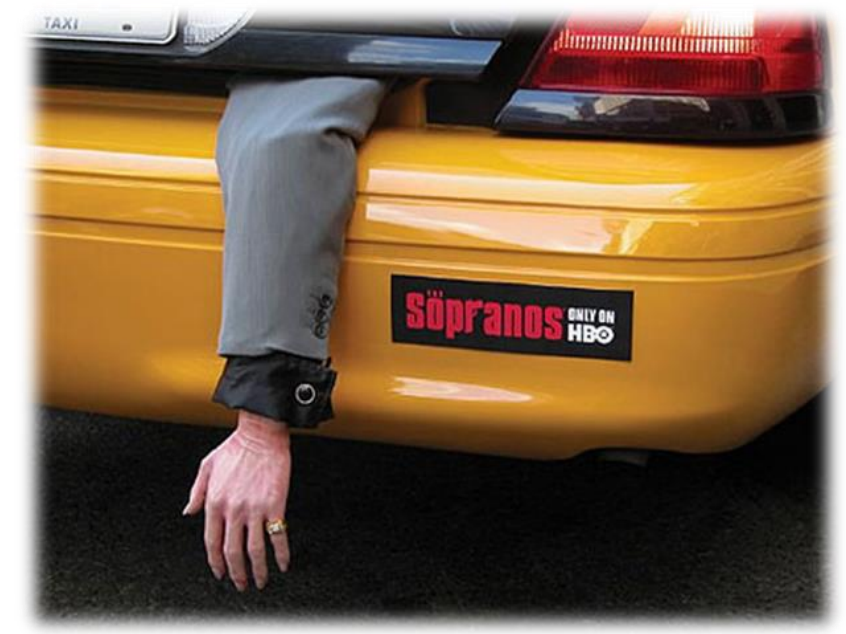

Figura 2. Imagen de la Campaña de TV HBO en Taxis de New York. Fuente: www.google.images

Facultad de Ciencias de la Información - Universidad de La Laguna Avenida César Manrique, s/n; Campus de Guajara 38071 La Laguna, Tenerife (Islas Canarias - España) 
Los estudiantes valoraron este tipo de comunicación por la técnica del efecto sorpresa, la singularidad y el contexto en el cual se detallaba la intrusión de un cadáver, creando la ilusión y sensación de veracidad.

Otras de las recientes acciones más recordadas en la investigación fue la acción de street o marketing de guerrilla de la cadena de drama TNT que sorprendió en varios países nórdicos europeos con una performance en la que varios actores simulaban la recreación de un secuestro, atraco y tiroteo en medio de un lugar público y estratégico del centro de varias ciudades como Bruselas y Luxemburgo. La acción supuso un gran acierto con la propuesta del contenido de la cadena de televisión, ya que ofrecía drama en estado puro.

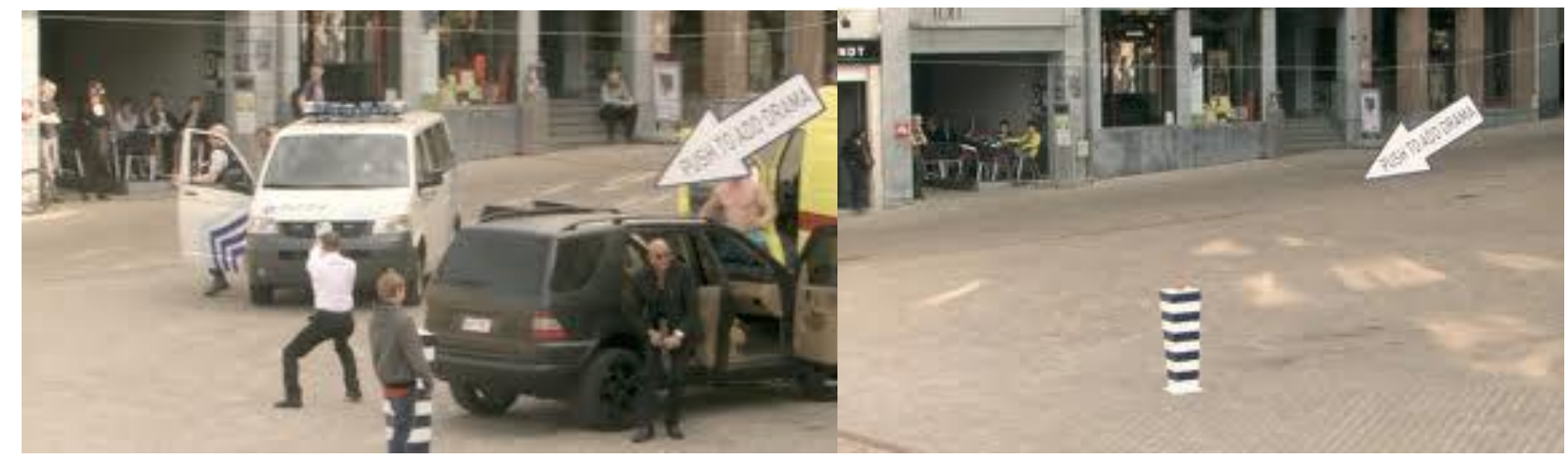

Figuras 3 y 4. Imágenes de la Campaña de Street de la Cadena TNT en Bruselas. Fuente: www.google.es/imágenes

Según Sánchez Herrera y Pintado (2010: 25), la gran ventaja de este tipo de publicidad es que el canal no está saturado y cuenta con el elemento sorpresa sobre el ciudadanoviandante-consumidor. Debido a que este público es menos impresionable, demanda fórmulas más agresivas ante la contaminación visual exterior, el receptor cada vez se sorprende menos con los mensajes publicitarios que recibe a través de los medios convencionales; por tanto se ha impuesto la necesidad de nuevos y mejores medios para llegar al receptor de forma más eficaz y directa.

Estas acciones tienen un alto poder persuasivo. El emisor emite un estímulo, si este estímulo es recibido por el receptor como original, novedoso, provocador y seductor, provocará una alta implicación, cambio de actitud o persuasión. Estas nuevas acciones de comunicación y marketing están cada vez más de moda, pero no hay que olvidar que también se puede 
correr el riesgo de llegar a ser excesivamente intrusivo, es decir, interrumpir de una forma demasiada agresiva el día a día del ciudadano.

Otras acciones de street valoradas a través de la búsqueda en Internet fue la acción de Heineken del candidato y la acción de ambient marketing de Coca-Cola.

En el caso de la marca Heineken, la búsqueda de un candidato para formar parte del staff de la empresa se convierte en eje de la comunicación de la campaña. Una estrategia que consiguió convertirse rápidamente en viral y que afianzó la imagen de marca de la compañía. A través de diferentes situaciones comprometidas en entrevistas de trabajo poco convencionales y emitidas online, conectaron con el target para que participara en la elección del candidato a través de los votos generados en Internet.

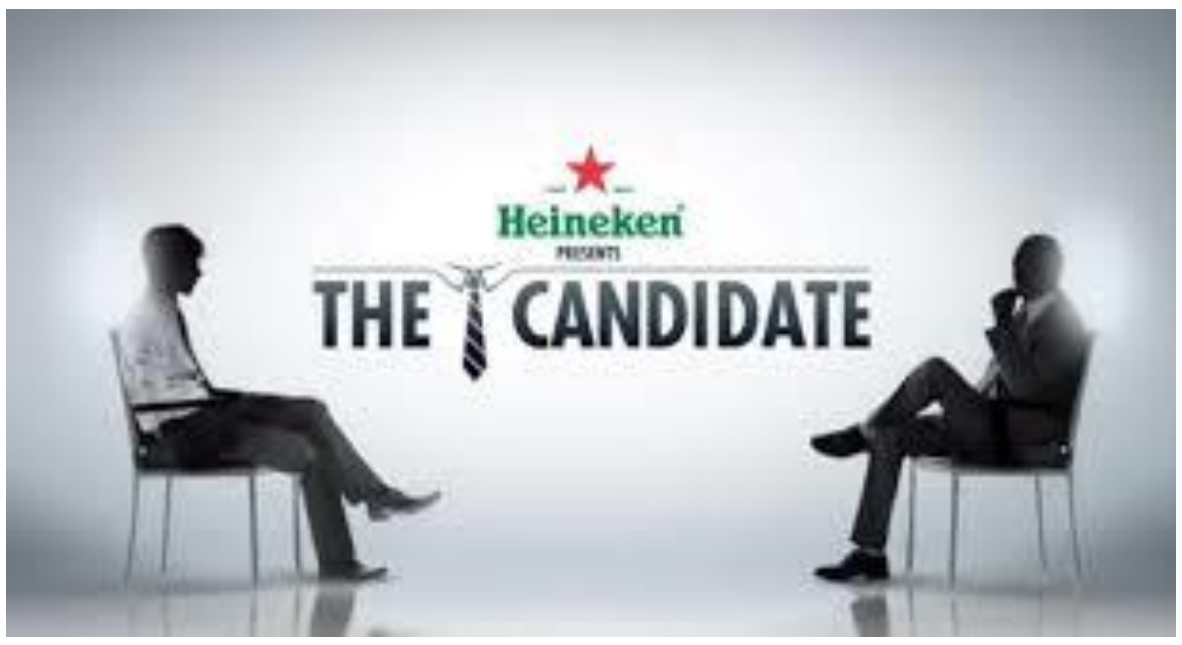

Figura 5. Imagen principal de la acción de Heineken El Candidato. Fuente: www.google.es/imágenes

No se podía olvidar la marca emblemática por excelencia, Coca-Cola. En esta ocasión también ha sido escogida por la muestra como ejemplo de efecto sorpresa, interacción y viralidad. A través de la transformación de una marquesina con efecto imán, los viandantes que esperaban el autobús en países como en Francia, se quedaban adheridos a la marquesina de la marca Coca-Cola. Esta acción pretendía comunicar las características y cualidades del nuevo envase de la marca que contaba con un nuevo relieve para poder coger mejor el envase. 


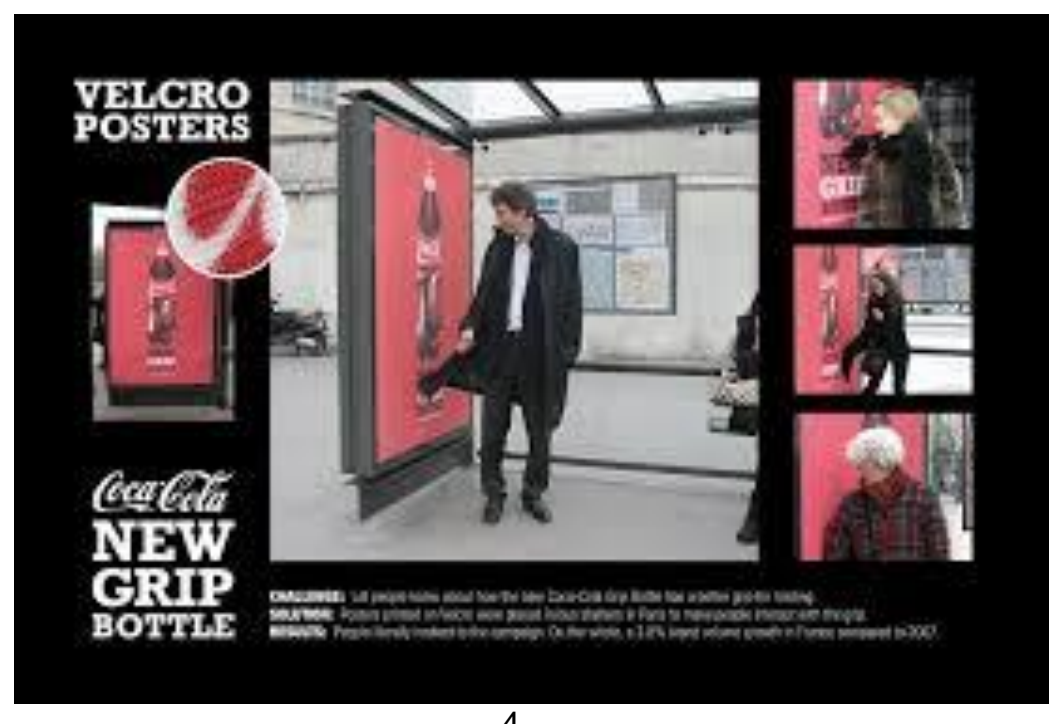

4.

Figura 6. Imagen de ambient marketing de Coca-Cola.

Fuente: www.google.es/imágenes

En España, recientemente en el año 2013 el mobiliario urbano también puede transformarse y donde antes se veía una columna, ahora se puede encontrar: Una botella de la marca Solán de Cabras.

Arena Media (la agencia de medios integrada del Grupo Havas Media) y JCDecaux desarrollaron una acción de Ambient Marketing en mobiliario urbano a través de la cual los soportes tipo columnas de algunas de las calles más estratégicas de Madrid se convirtieron en grandes botellas de agua de la marca Solán de Cabras. 


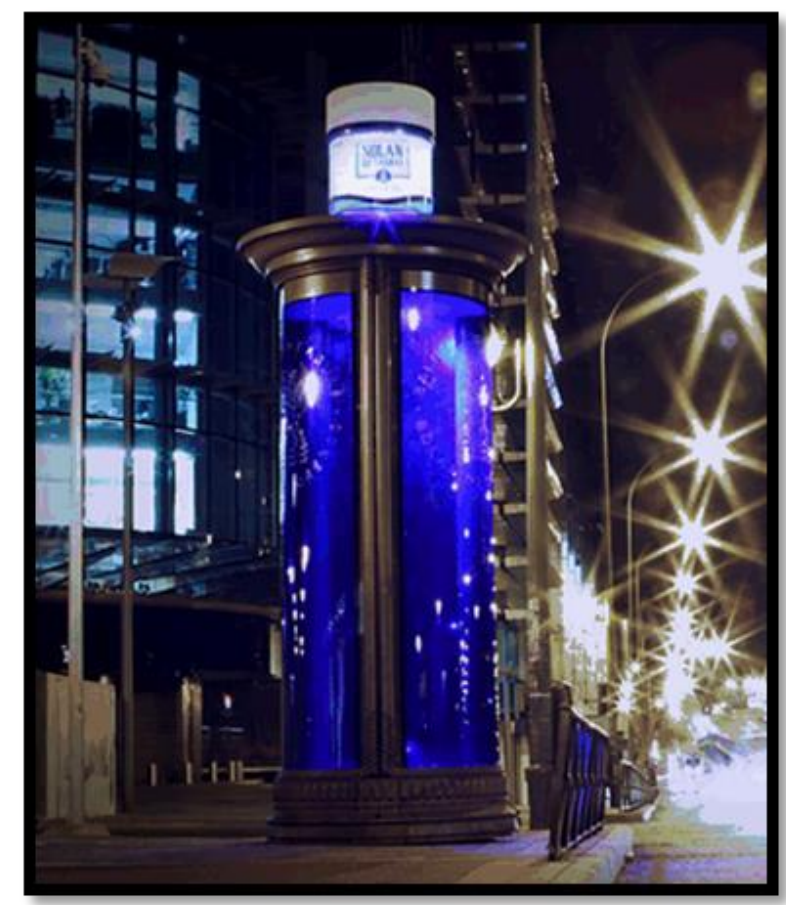

Figura 7. Imagen del envase de Solán de Cabras en las calles de Madrid. Fuente: www.google.es/imágenes

Las columnas estaban fijadas en las calles de Goya esquina Príncipe de Vergara, en el Paseo del Prado esquina Plaza de Cibeles, en el Paseo de la Castellana, en la calle Raimundo Fernández Villaverde esquina Orense y en la esquina de la Calle Princesa con la Plaza de España. Todas ellas pensadas por el gran tránsito de vehículos y de personas que se dan en ellas.

El objetivo principal de esta campaña era transformar las aburridas columnas donde se inserta la multitud de impactos publicitarios, en divertidas gigantes botellas de agua. Como puede comprobarse la creatividad puede ser muy sencilla pero a la vez ser espectacular. En este caso, Solán de Cabras apuesta por un público amplio, situándose más en el perfil del target joven-adulto, que son los que de verdad consumen agua embotellada.

Esta acción se ha ideado para apoyar el lanzamiento de la nueva gama de envases de plástico que la marca comercializa en los puntos de venta al público general. Para ello se ha unificado el formato pasando a tener la misma forma que la botella icono de la marca, la botella de vidrio que Solán de Cabras distribuye en el canal restauración y hostelería. 
En el soporte publicitario no hay ni copy (textos) ni imagen, pero sí hay un mensaje que llama la atención claramente con un potente efecto recordatorio: una botella de agua de tres metros. La mayor parte de nosotros nos habríamos obsesionado con diseñar un cartel perfecto, sin ver lo fácil que es utilizar el propio soporte para recrear la botella de la marca, que es además su gran elemento diferenciador desde hace tiempo. El color azul 'eléctrico' y las formas del envase junto con la etiqueta en blanco es inconfundible para el consumidor.

El slogan aparece debajo de la marca en el que se puede leer: El Agua de la Vida muy adecuado y simple para un tipo de agua embotellada.

\section{Conclusiones}

La publicidad, los medios y los factores individuales y sociales influyen en las personas. Cuando estos últimos se debilitan, la influencia de los medios es directa y su poder se fortalece, tal como afirma Gianni Losito (1994: 85). Este es el caso de categorías sociales como la infancia y la tercera edad que se consideran débiles y cuyos instrumentos culturales no les permiten defenderse de la influencia de la publicidad.

Por ello, es necesario protegerles tanto de la publicidad como de los medios en general a través de sistemas de control y de normas jurídicas. En ocasiones, la publicidad y los medios de comunicación buscan sus propios intereses, hieren la sensibilidad de las personas con mensajes violentos y vulgares transgrediendo los tabúes sociales. Para evitar esto, es necesario desarrollar en los adultos una capacidad crítica, y no de censura, hacia los medios y el papel que desarrolla la publicidad en nuestra sociedad. $Y$ aunque la regulación jurídica determine unos límites a la publicidad, ésta tiene el derecho de ofrecer sus productos o sus servicios en el mercado a un público lo más amplio posible. Esto es necesario para que cada consumidor tenga la mayor oferta posible y pueda realizar la mejor elección. Para algunos bastaría con ofrecer una información fundamentada en la veracidad y la razón y no apelar a la emoción, como se hace habitualmente. Sin embargo, si la publicidad se basara en serios y racionales argumentos, el ambiente cultural y social sería más triste y aburrido.

Dicho esto, la publicidad no es en sí misma ni buena ni mala como la televisión, el cine u otros medios de comunicación. Por consiguiente, la publicidad por sí misma es buena y sólo puede convertirse en algo malo si se hace un mal uso o con intencionalidad de engañar a otras personas; en cuyo caso, la responsabilidad no es sólo de la publicidad, que está regulada por leyes y códigos de autodisciplina, sino de otros agentes que no desarrollan su función de forma adecuada.

Facultad de Ciencias de la Información - Universidad de La Laguna

Avenida César Manrique, s/n; Campus de Guajara

38071 La Laguna, Tenerife (Islas Canarias - España)

www.revistapangea.org | Pág. 35 
La publicidad no se puede conformar con los medios convencionales como la televisión, radio o prensa, es indispensable que se acerque a la gente, y la publicidad exterior a través de sus diversas variantes puede proporcionar ese elemento necesario para interactuar con la gente que circula por la calle.

Este hecho ha llevado a numerosos errores, llegando a causar en las personas un efecto negativo, una repulsión que otorga a la publicidad un carácter aburrido y pesado, que sólo pretende conseguir el incremento del consumismo. Sin embargo, con el tiempo se está evolucionando hacia nuevas formas que intente limpiar un poco la imagen que la publicidad exterior se ha ganado durante años.

Es obvio que el marketing tradicional se está adaptando a los nuevos canales interactivos en la divulgación de mensajes de toda índole. Gracias a la Web la distribución y el poder de la información publicitaria es sorprendente y más aún si entendemos toda la estrategia de Social Media que se está originando a través de las Redes Sociales.

Hoy día, para construir estrategia de Marca, Branding Corporate, lo mismo se difunde un spot en Tv que se convoca por Facebook el encuentro de miles de personas en un espacio público para bailar la Samba y se crea un concurso a partir de dicha convocatoria en determinada zona pública. La tendencia es que el consumidor adopte un papel/rol totalmente participativo y no pasivo. Debe construir el mensaje, ayudar a la marca a conseguir sus objetivos y es por ello que el consumidor comienza a establecer una comunicación con la marca meramente horizontal y no vertical como lo hace con los medios tradicionales. Marca y usuario están al mismo nivel en las reglas del juego.

Ahora, se participa en la construcción del propio modelo de discurso publicitario. El paradigma comunicacional está cambiando frente a los nuevos cambios y posibilidades que otorga la tecnología, la innovación y los nuevos canales. Tal es el caso de la marca Freixenet que desde hace unos años, invita a participar al usuario, al consumidor, receptor o ciudadano a crear, producir y distribuir la campaña publicitaria. En esa búsqueda de participación, de compartir experiencia con la marca es el diagnóstico de los nuevos formatos publicitarios. Entrar en el espacio físico y psíquico (mental) del consumidor o futuro consumidor para no únicamente que compre, sino que conviva con la marca para siempre.

El mundo publicitario y de las marcas debería pues, darse cuenta de que hoy día no vale con intentar vender un producto y saturar con mensajes e imágenes que muestran lo mismo de siempre, sino que hay que acercarse a la gente, hay que hacer partícipes a los ciudadanos de una manera amena y divertida. 
Es evidente que las acciones menos convencionales están haciendo que las grandes marcas, conocidas y no tan conocidas, apuesten por estos formatos que parten de un enfoque quizá más local inicialmente para convertirse al final del proceso en acciones más globales, gracias a la viralidad que otorga la web 2.0.

La era tecnológica en la que nos desenvolvemos actualmente, está proporcionando una evolución o revolución de estos soportes externos y sobretodo está potenciando la interactividad con los públicos y consumidores, pero sin lugar a dudas este tema sería ya objeto de estudio de otro artículo de opinión.

No debemos olvidar que las acciones Btl, (below the line, por debajo de la línea) en muchas ocasiones, son complemento de acciones convencionales que se utilizan como necesidad social para alcanzar a minorías con el mensaje publicitario. Resulta lógico pensar que debido al marco social, económico y cultural en el que nos encontramos las acciones Btl ofrecen ventajas más económicas que otros medios tan conocidos como la Televisión. Además, si se tiene en cuenta que uno de los principales objetivos de los mensajes Below the line es conseguir repercusión mediática de forma gratuita, se tiene garantizada la utilización de estos mensajes por parte de las marcas.

El panorama es que esta comunicación alternativa siga creciendo y desarrollándose en vistas de todas sus posibilidades creativas, económicas y sociales. Por tanto, se espera en un futuro una explosión de mensajes publicitarios cargados de innovación y presentes en cualquier espacio de nuestro día a día.

\section{Discusiones}

En general, el objetivo principal de este tipo de acciones Below the Line es hacer comunicación de marca, al igual que muchas otras acciones convencionales de marketing, pero de una forma más original y llegando a un consumidor saturado de mensajes de una forma indirecta y creando estímulos no tan agresivos y directos como lo hace la publicidad y el marketing tradicional. El consumidor procesa estos mensajes como información divertida y simpática hacia una marca concreta, por lo que el refuerzo de Top of mind de la marca es mucho mayor (Matellanes, 2013: 18).

Por otro lado, también se debe tener en cuenta que toda herramienta de marketing puede presentar en ocasiones ciertas limitaciones:

Es cierto que este tipo de campañas son acciones no controladas por las compañías de medios por lo que cualquier posible segmentación resulta más difícil de realizar.

Facultad de Ciencias de la Información - Universidad de La Laguna

Avenida César Manrique, s/n; Campus de Guajara

38071 La Laguna, Tenerife (Islas Canarias - España)

www.revistapangea.org | Pág. 37 
Es un hecho que el Street marketing como herramienta resulta muy interesante, pero debe manejarse adecuadamente para obtener resultados óptimos, no vale salir a la calle y hacer cualquier cosa, son acciones que requieren una planificación, hay que estudiar qué se va a hacer, dónde, cuándo y de qué manera. Hay que escoger de forma estratégica los lugares para poner en marcha este tipo de campañas por ejemplo, es interesante que sean lugares públicos de gran concentración y afluencia de transeúntes, no todo debe ser sorpresa.

Además, se debe ser muy cuidadoso para no ser invasivos es decir, está bien sorprender al consumidor en su día a día, pero no se debe interrumpir su vida o su ocio, hay que establecer los límites entre lo que puede resultarle sorprendente y agradable y lo que podría parecerle agresivo.

El panorama es que esta comunicación alternativa siga creciendo y desarrollándose en vistas de todas sus posibilidades creativas, económicas y sociales. Por tanto, nos espera en un futuro una explosión de mensajes publicitarios cargados de innovación y presentes en cualquier espacio de nuestro día a día.

\section{Bibliografía}

Alberoni, F. (1964). Consumi e società. Bologna: Il Mulino.

Barthes, R. (1957). Mythologies. París: Seuil.

Baudrillard, J. (1987). Il sogno della merce. Milano: Lupetti.

Berman, R. (1981). Advertising and Social Change. Beverly Hills-London-New Delhi: Sage.

Cervera Fantoni, A.L. (2008). Comunicación Total. Madrid: Esic.

Codeluppi, V. (1996). La società pubblicitaria. Consumo, mass media, ipermodernità, Genova, Costa \& Nolan.

Corrigan, P. (1997). The Sociology of Consumption: an Introduction. London-Thousand OaksNew Delhi: Sage.

Galbraith, J.k. (1958). The Affluent Society. London: Andre Deutsch.

Giaccaacca , C. (1995). I luoghi del quotidiano. Pubblicità e costruzione della realtà sociale. Milano: Angeli.

Goffman, E. (1979). Gender Advertisements. New York: Harper \& Row.

Groupe Marcuse (2004). De la misère humaine en milieu publicitaire. París: La Decouverte.

Holbrook, M. (1987). Mirror, Mirror, on the Wall, What's Unfair in the Reflections on Advertising?. Journal of Marketing, July, 95-103. 
Klein, N. (2000). No Logo: Taking Aim at the Brand Bullies. New York: Picador.

Lasn, k. (1999). Culture Jam: How to Reverse America's Suicidal Consumer Binge. New York: Harper Collins.

Losito, G. (1994). II potere dei media. Roma: La Nuova Italia Scientifica.

Marcuse, H. (1964). One-Dimensional Man. Boston: Beacon Press.

Matellanes Lazo, M.; (2013). Ambient Marketing y Street Marketing. Harvard Deusto Márketing y Ventas, № 16, pp. 16-23. Ediciones Deusto.

Pacackard, V. (1957). The Hidden Persuaders. New York: David McKay.

Pacheco Rueda, M. (1998). Dimensión Social de la Publicidad Exterior. Revista Latina de Comunicación Social, 8. Recuperado el 15 de noviembre de 2013 en http://www.ull.es/publicaciones/latina/a/59mar.htm.

Pollay, R. (1986). The Distorted Mirror: Reflections on the Unintended Consequences of Advertising. Journal of Marketing, April, 18-36.

Sánchez Herrera, J. \& Pintado Blanco, T. (2010). Nuevas Tendencias en Comunicación. Madrid: Esic.

Sitios Web consultados:

Página Web de Casos de Marketing: www.casosdemarketing.com (varias consultas).

Página Web de Informa BTL: www.informabtl.com (varias consultas).

\section{Forma de citar este artículo en bibliografías}

MATELLANES, M. (2014): Análisis del funcionamiento de la Publicidad Below The Line en la Sociedad, en Revista PANGEA, 5, páginas 22 a 39. Red Académica lberoamericana de Comunicación. Recuperado el _ de _ _ de 2_ de: http://www.revistapangea.org

\footnotetext{
${ }^{i}$ Realizar parodias de acciones comerciales y publicitarias de marcas reconocidas.
} 